\title{
Glomerulonephritis preceding late relapse of Hodgkin's disease
}

\author{
W.A. Lynn and R.E. Marcus ${ }^{1}$ \\ Departments of Medicine and ${ }^{1}$ Haematology, Hillingdon Hospital, Uxbridge, Middlesex UB8 3NN, UK.
}

\begin{abstract}
Summary: We report a case of focal sclerosing glomerulonephritis which developed 11 years after successful treatment of nodular sclerosing Hodgkin's disease. Hodgkin's disease relapsed 7 months later and responded completely to combination chemotherapy with simultaneous improvement in renal function. This case shows that relapse of Hodgkin's disease may occur after a 10 year interval and furthermore it may be preceded by nephrotic syndrome. Renal disease in such cases may not recover until the underlying Hodgkin's disease is treated.
\end{abstract}

\section{Introduction}

Glomerulonephritis is a well recognized complication of Hodgkin's disease, ${ }^{1}$ and nonHodgkin's lymphoma. ${ }^{2,3}$ In some reports it has preceded clinical Hodgkin's disease ${ }^{4}$ in others it has occurred at the time of presentation. ${ }^{1}$ It has also been described after successful induction of remission. ${ }^{5}$ We present a patient in which late relapse of Hodgkin's disease was preceded by glomerulonephritis which resolved only after combination cytotoxic chemotherapy.

\section{Case report}

A 62 year old female schizophrenic presented in September 1975 with malaise, weight loss and axillary lymphadenopathy. Clinical examination revealed hepatomegaly. Renal function was normal and there was no proteinuria. Axillary node biopsy showed nodular sclerosing Hodgkin's disease, and she was treated with MOPP (mustine, vincristine, procarbazine and prednisolone. ${ }^{6}$ She entered complete remission after two courses and received a total of four cycles of therapy.

She remained well until April 1986 when she developed ankle oedema with proteinuria. Investigations at that time showed: blood pressure $140 / 90 \mathrm{mmHg}$, haemoglobin $12.4 \mathrm{~g} / \mathrm{dl}$, erythrocyte sedimentation rate (ESR) $70 \mathrm{~mm} / \mathrm{h}$, sodium $136 \mathrm{mmol} / 1$, potassium $4.6 \mathrm{mmol} / 1$, urea $18.2 \mathrm{mmol} / 1$, creatinine $648 \mu \mathrm{mol} / \mathrm{l}$, albumin $16 \mathrm{~g} / \mathrm{l}, \quad 24$-hour urinary protein $20.4 \mathrm{~g} / 1$ (non-selective pattern) and

Correspondence: W.A. Lynn, M.B., B.S., M.R.C.P.

Accepted: 4 December 1987 creatinine clearance $4 \mathrm{ml} / \mathrm{min}$. Her renal function deteriorated and haemodialysis was instituted. Renal biopsy consisted of 12 glomeruli of which 4 showed hyaline sclerosis with granular deposition of IgM and $\mathrm{C} 3$ within the abnormal glomeruli consistent with a diagnosis of focal sclerosing glomerulonephritis. She was dialysed for 6 weeks with improvement in renal function. However, her serum creatinine remained elevated and she continued to have proteinuria. In June 1986 she received a 6-week course of oral prednisolone starting at $60 \mathrm{mg}$ daily and reducing by $10 \mathrm{mg}$ per week.

In November 1986 she again presented with axillary lymphadenopathy. Haemoglobin was $13.2 \mathrm{~g} / \mathrm{dl}$, ESR $67 \mathrm{~mm} / \mathrm{h}$, serum albumin $30 \mathrm{~g} / \mathrm{l}$, creatinine $253 \mu \mathrm{mol} / 1$, 24-hour urinary protein $2.6 \mathrm{~g} / \mathrm{l}$ and creatinine clearance $17 \mathrm{ml} / \mathrm{min}$. Computerized tomography also showed mediastinal lymphadenopathy. Biopsy of the axillary mass confirmed recurrent nodular sclerosing Hodgkin's disease. She was given LOPP (vincristine, chlorambucil, procarbazine and prednisolone). ${ }^{6}$ She entered complete remission after two courses and in view of her frailty only four cycles of therapy were given. Renal function improved steadily during this period and at follow-up 3 months later there was no evidence of Hodgkin's disease, her serum creatinine was $96 \mu \mathrm{mol} / 1$, creatinine clearance $85 \mathrm{ml} / \mathrm{min}$ and the proteinuria less than one gram in 24 hours.

\section{Discussion}

Late relapse of Hodgkin's disease is extremely rare. The majority of patients relapse within the first 2

(C) The Fellowship of Postgraduate Medicine, 1988 
years, with smaller numbers between 2 and 5 years. In the Stanford series of 1225 consecutive patients treated between 1961 and $197739 \%$ relapsed overall. Of these only six relapsed after remaining disease-free for more than 5 years, and in only one case did Hodgkin's disease recur after more than 10 years. ${ }^{7}$ Other series confirm this pattern of disease recurrence. ${ }^{8.9}$ In a recent analysis of 692 patients with stage III or IV Hodgkin's disease, submitted to the British National Lymphoma Investigation (BNLI), only seven patients relapsed after more than 5 years of complete remission and in only one case relapse occurred after a disease-free interval of 10 years (BNLI, personal communication).

Glomerulonephritis associated with Hodgkin's disease is well described although uncommon. The renal histology of 24 cases was reviewed in $1976,{ }^{10} ; 66 \%$ of cases showed minimal change glomerulonephritis, $20 \%$ were membranous glomerulonephritis and $14 \%$ were not classified. Another series $^{11}$ reveals a similar distribution, but crescentic glomerulonephritis ${ }^{12}$ and focal sclerosing glomerulonephritis ${ }^{13.14}$ have also been described. The renal condition occurs most frequently at the time of presentation with Hodgkin's disease. ${ }^{1}$ It may, however, precede clinically detectable Hodgkin's disease, although only two cases have been reported where this interval was more than one year. ${ }^{4,15}$ Two cases have also been reported where glomerulonephritis developed after clinical remission of Hodgkin's disease. ${ }^{5}$ However, both cases subsequently received immunosuppressive therapy for their glomerulonephritis and therefore suppression of subclinical Hodgkin's disease cannot be excluded.

In our case renal function was normal until her presentation with the nephrotic syndrome. The episode of acute renal failure was probably due to acute tubular necrosis. This would explain her partial recovery in renal function after a short period of haemodialysis. However, her renal function remained abnormal until treatment of recurrent Hodgkin's disease when it rapidly returned to normal. It is also possible that the oral prednisolone given during June and July had a temporary suppressing effect on her nephrotic

\section{References}

1. Plager, J. \& Stutzman, L. Acute nephrotic syndrome as a manifestation of active Hodgkin's disease. $A m \mathrm{~J}$ Med 1971, 50: 56-66.

2. Belghiti, D., Vernant, J., Hirbec, G., Gubler, M., Andre, C. \& Sobel, A. Nephrotic syndrome associated with T-cell lymphoma. Cancer 1981, 47: 1878-1882. syndrome or under underlying Hodgkin's disease or both.

Moorthy in $1976^{16}$ reviewed 33 cases of nephrotic syndrome associated with Hodgkin's disease. Twenty-one patients received chemotherapy with remission of the nephrotic syndrome in all cases, 9 cases received radiotherapy alone with resolution of renal disease in 7 , in 2 patients surgical excision of nodes was the only treatment and the nephrotic syndrome resolved in both cases. This would suggest that the renal lesion depends upon the presence of active Hodgkin's disease. Effective therapy is then followed by recovery in renal function.

The mechanism of renal damage is unclear but direct tumour infiltration or amyloid deposition were not seen in these series. It has been proposed that renal damage may result from a nephrotoxic substance released by Hodgkin's disease cells, ${ }^{1}$ by local effects of abnormal $\mathrm{T}$ lymphocytes ${ }^{16}$ or by tumour antigens inducing immune-complex mediated glomerular damage. ${ }^{17}$ It is of interest that focal sclerosing glomerulonephritis without associated Hodgkin's disease generally responds poorly to therapy and tends to lead to progressive renal impairment. ${ }^{18}$ In this case and others ${ }^{13,14}$ there was recovery of renal function after treatment of the Hodgkin's disease. This suggests that focal sclerosing glomerulonephritis may have a different prognosis when associated with Hodgkin's disease. Alternatively, removing the stimulus for further renal damage may allow recovery of kidney function.

The combination of nephrotic syndrome and Hodgkin's disease is rare. Nevertheless this possibility should be entertained and excluded when a patient with a past history of treated Hodgkin's or non-Hodgkin's lymphoma presents with renal disease, especially in those patients where renal replacement therapy might not otherwise be contemplated.

\section{Acknowledgements}

Our thanks to Dr L. H. Sevitt and Dr R. Britt for permission to report on their patient.

3. Giron Gonzalez, J.A., Yebra Bango, M., Merino Morales, F., Menedez Caro, J.L., Diego Marin, F.J. \& Durantez Martinez, A. The association of nonHodgkin's lymphoma with glomerulonephritis. Postgrad Med J 1986, 62: 1141-1145. 
4. Huisman, R.M., de Jong, P.E., de Zeeuw, D., van Imhoff, G.W. \& van der Hem, G.K. Nephrotic syndrome preceding Hodgkin's disease by 42 months. Clin Nephrol 1986, 26: 311-313.

5. Shapiro, C.M., Vander Laan, B.F., Jao, W. \& Sloan, D.E. Nephrotic syndrome in two patients with cured Hodgkin's disease. Cancer Res 1972, 31: 1828-1833.

6. Hancock, D.W. Randomised study of MOPP against LOPP in advanced Hodgkin's disease. Radiother Oncol 1986, 7: 215-221.

7. Kaplan, H. In: Hodgkin's Disease. Harvard University Press, 1980. pp 549-597.

8. Frei, E. \& Gehan, E.A. Definition of a cure for Hodgkin's disease. Cancer Res 1972, 31: 1828-1833.

9. de Vita, V.T., Simon, R.M., Hubbard, L.M. et al. Curability of advanced Hodgkin's disease - long term follow up of MOPP treated patients at the National Cancer Institute. Ann Intern Med 1972, 92: 587-595.

10. Gagliano, R.G., Costanzi, J.J., Beathard, G.A., Sarles, H.E. \& Bell, J.D. The nephrotic syndrome associated with neoplasia: an unusual paraneoplastic syndrome. Am J Med 1976, 60: 1026-1031.

11. Routledge, R.C., Hann, I.M. \& Jones, P.H. Hodgkin's disease complicated by the nephrotic syndrome. Cancer 1976, 38: 1735-1740.
12. Petzel, R.A., Brown, D.C., Staley, N.A., McMillen, J.J., Sibley, R.K., \& Kjellstrand, C.M. Crescentic glomerulonephritis and renal failure associated with malignant lymphoma. Am J Clin Pathol 1979, 71: 728-732.

13. Phillips, M., Neild, G.H., Cameron, J.S., Williams, D.G. \& Amlot, P. Hodgkin's disease and focal glomerulosclerosis (letter). $N$ Engl J Med 1983, 309: 1389-1390.

14. Watson, A., Stachura, I., Fragola, J. \& Bourke, E. Focal glomerulosclerosis in Hodgkin's disease. Am J Nephrol 1983, 3: 228-232.

15. Kramer, P., Sizoo, W. \& Twiss, E.E. Nephrotic syndrome in Hodgkin's disease. Neth J Med 1981, 24: 114-119.

16. Moorthy, A.V., Zimmerman, S.W. \& Burkholder, P.M. Nephrotic syndrome in Hodgkin's disease. Am J Med 1976, 61: 471-477.

17. Froom, D.W., Franklin, W.A., Hano, J.E. \& Potter, E.V. Immune deposits in Hodgkin's disease with nephrotic syndrome. Arch Pathol 1980, 94: 547-553.

18. Glassock et al. Primary glomerular diseases. In: The Kidney, 2nd edition. Saunders, W.B., Philadelphia, 1981. 